\title{
PEMBERDAYAAN MASYARAKAT MELALUI PENGHIJAUAN UNTUK KONSERVASI SUMBER AIR BANYUNING KOTA BATU
}

\author{
Nila Restu Wardani ${ }^{1}$, Dwi Fauzia Putra ${ }^{2}$ \\ ${ }^{1,2}$ Pendidikan Geografi, Ilmu Pendidikan, Universitas Kanjuruhan Malang \\ Jl. S. Supriadi No. 48 Malang \\ $\underline{\text { nilarestu@unikama.ac.id }}^{1}$, dwifauzia@unikama.ac.id $^{2}$
}

\begin{abstract}
ABSTRAK
Sumber air Banyuning merupakan salah satu sumber air yang ada di hulu Sungai Brantas Kota Batu. Sumber air ini dimanfaatkan masyarakat Kecamaan Bumiaji untuk kebutuhan sehari-hari dan sebagai sumber irigasi. Permasalahan yang terjadi yaitu degradasi lahan di sekitar sumber air. Lahan ini seharusnya dijadikan tempat konservasi sumber daya air. Lahan di sekitar sumber air merupakan milik petani dan ditanami bunga Rotensia yang tidak memiliki perakaran kuat. Berdasarkan kondisi ini dilakukan pemberdayaan masyarakat petani untuk melakukan penghijauan dengan menanam bibit pohon jeruk. Bibit pohon jeruk dipilih karena jika pohon ini sudah besar memiliki perakaran yang kuat sehingga mampu menahan laju erosi, menjadi resapan air hujan, dan memiliki nilai ekonomis dari hasil panen buah jeruk. Hasil dari kegiatan pemberdayaan masyarakat ini yaitu: 1) Meningkatkan partisipasi masyarakat dalam konservasi sumber daya air; 2) Meningkatkan kesadaran lingkungan masyarakat untuk menjaga kelestarian sumber daya air; 3) Menambah jumlah pohon tegakan dengan perakaran kuat di lahan sekitar sumber air yang memiliki kemiringan lereng lebih dari $40^{\circ}$.
\end{abstract}

Kata Kunci: pemberdayaan masyarakat, penghijauan, konservasi sumber air

\begin{abstract}
Banyuning water resource is one of the water resource in the upstream of the Brantas River in Batu City. This water resource is used by the Bumiaji District community for daily needs and as a source of irrigation. The problem that occurs is land degradation around water sources. This land should be used as a place to conserve water resources. The land around the water resource is owned by farmers and planted with Rotensia flowers that do not have strong roots. Based on these condition, the empowerment of the farming community is carried out by afforestation with orange trees. Orange tree seedlings are chosen because it has a strong root for withstand of erosion, absorb rainwater, and has the economic value of the orange fruits harvest. The results of these community empowerment activities are: 1) Increasing community participation in water resources conservation; 2) Increase community environmental awareness to preserve water resources; 3) Increase the standing trees with strong roots in the land around the water resource which has a slope of more than $40^{\circ}$.
\end{abstract}

Keywords: community empowerment, afforestation, conservation of water resource

\section{PENDAHULUAN}

Sumber daya alam yang paling utama dibutuhkan makhluk hidup adalah air. Air merupakan kebutuhan makhluk hidup yang paling hakiki, termasuk manusia, tanaman dan hewan. Oleh sebab itu air perlu ditata pengelolaannnya agar memberikan manfaat bagi rakyatnya. Dalam jaringan distribusi air, diperlukan suatu sistem yang terkoordinasi, baik 
antara para pelaku maupun pembuat kebijakan di sektor perairan, dan jaminan perolehan air yang cukup.

Sumber daya air merupakan salah satu unsur yang sangat penting untuk keberlanjutan kehidupan makhluk hidup terutama manusia. Keberadaan air dapat berperan multiguna, dapat digunakan sebagai air minum dan MCK (mandi, cuci, kakus), mengairi lahan pertanian, dan ekonomi. Maka diperlukan adanya suatu pengelolaan terhadap sumber daya air agar keberadaannya tetap bermanfaat dan berkelanjutan untuk kepentingan jangka panjang.

Salah satu bentuk pengelolaan sumber daya air adalah HIPPAM. HIPPAM (Himpunan Penduduk Pemakai Air Minum) merupakan organisasi pengelolaan air minum lokal yang dibangun masyarakat. Sistem ini dibentuk dari ketidaksamaan persepsi masyarakat lokal dengan pemerintah tentang pegelolaan sumber daya air. PDAM Kota Batu menjadikan sumber daya air sebagai bisnis dan masyarakat sebagai konsumen. Biaya yang mahal dan pelayanan yang tidak memuaskan oleh PDAM ini yang selanjutnya membuat masyarakat keluar sebagai pelanggan dan mendirikan HIPPAM.

HIPPAM memanfaatkan potensi sumber air yang dimiliki yaitu sumber air Banyuning. Sumber air ini terletak di sebelah utara Dusun Banyuning Desa Punten Kecamatan Bumiaji Kota Batu. Sumber air Banyuning terletak pada ketinggian 854 m dpl. Sumber air Banyuning tidak hanya dimanfaatkan masyarakat Dusun Banyuning, tetapi masyarakat di beberapa desa di Kecamatan Bumiaji. Sumber air Banyuning berada pada hulu Sungai Brantas yang merupakan kawasan konservasi.

Di sekitar sumber air Banyuning merupakan lahan pertanian milik masyarakat sekitar. Lahan pertanian ini ditanami bunga Rotensia yang memiliki nilai ekonomis tinggi. Alasan petani menanam bunga Rotensia karena harga jual mahal dan dekat dengan sumber air, sehingga lebih mudah untuk irigasi. Penanaman bunga seharusnya tidak dilakukan di tanah dengan kemiringan lebih dari $40^{\circ}$.

Berdasarkan kondisi di lapangan, maka masyarakat petani bunga di sekitar sumber air Banyuning diberdayakan dengan menanam pohon. Penanaman pohon dengan perakaran yang kuat dan masih memiliki nilai ekonomis tinggi serta tanaman bunga Rotensia juga masih bisa ditanam di sekitar pohon yang ditanam. Salah satu tanaman yang dipilih untuk ditanam di sekitar air Banyuning adalah jeruk keprok punten.

Sumber air Banyuning terbukti mampu memberikan manfaat besar masyarakat Desa Punten dan hampir seluruh desa di Kecamatan Bumiaji memanfaatkan sumber air ini untuk 
pemenuhan kebutuhan air sehari-hari. Maka dari itu pelestarian sumber air sangat penting dilakukan dengan penanaman pohon.

Berdasarkan kondisi di lapangan, maka permasalahan yang terjadi sebagai berikut.

1) Pohon tegakan di sekitar sumber air Banyuning mulai berkurang.

2) Di sekitar sumber air Banyuning merupakan lahan pertanian milik masyarakat sekitar yang ditanami bunga Rotensia. Bunga ini tidak memiliki perakaran kuat, sehingga jika terjadi hujan lebat pada lahan yang memiliki kemiringan lebih dari $40^{\circ}$ maka berpotensi longsor.

\section{METODE}

Metode yang digunakan dalam pelaksanaan penghijauan ini adalah pendampingan dengan prakek langsung penanaman bibit jeruk di lahan petani yang berada di sekitar sumber air. Kegiatan awal yang dilakukan yakni pertemuan dengan petani bunga Rotensia. Pertemuan ini bertujuan untuk memberitahukan maksud dan tujuan penghijauan yang akan dilakukan. Berikut ini langkah-langkah pelaksanaan kegiatan berdasarkan permasalahan yang terjadi.

Tabel 1. Permasalahan dan Solusi

\begin{tabular}{|c|c|c|c|c|}
\hline No & Permasalahan & Metode Pelaksanaan & $\begin{array}{c}\text { Langkah-langkah } \\
\text { Kegiatan }\end{array}$ & $\begin{array}{c}\text { Partisipasi } \\
\text { Masyarakat }\end{array}$ \\
\hline 1 & $\begin{array}{l}\text { Pohon tegakan di } \\
\text { sekitar sumber air } \\
\text { Banyuning mulai } \\
\text { berkurang }\end{array}$ & $\begin{array}{l}\text { Observasi langsung ke } \\
\text { sumber air dan lahan } \\
\text { sekitarnya }\end{array}$ & $\begin{array}{l}\text { 1. Pencarian informasi } \\
\text { pemilik lahan di sekitar } \\
\text { sumber air } \\
\text { 2. Membuat kesepakatan } \\
\text { dengan petani pemilik } \\
\text { lahan di sekitar sumber } \\
\text { air untuk kegiatan } \\
\text { penanaman pohon }\end{array}$ & $\begin{array}{l}\text { Kesediaan petani } \\
\text { untuk menanami lahan } \\
\text { pertanian dengan } \\
\text { tanaman pohon yang } \\
\text { mimiliki perakaran } \\
\text { yang kuat, salah satu } \\
\text { bibit yang ditanam } \\
\text { adalah bibit jeruk } \\
\text { keprok punten. }\end{array}$ \\
\hline 2 & $\begin{array}{l}\text { Lahan pertanian } \\
\text { memiliki } \\
\text { kemiringan lereng } \\
\text { lebih dari } 40^{\circ} \\
\text { sehingga tidak } \\
\text { cocok ditanami } \\
\text { tanaman bunga } \\
\text { Rotensia dengan } \\
\text { perakaran serabut } \\
\text { yang tidak kuat } \\
\text { menahan air hujan }\end{array}$ & $\begin{array}{ll}\text { 1. } & \text { Diskusi } \\
\text { 2. } & \text { Pendampingan } \\
\text { kegiatan tanam } \\
\text { pohon }\end{array}$ & $\begin{array}{l}\text { 1. } \begin{array}{l}\text { Koordinasi dengan } \\
\text { petani bunga untuk }\end{array} \\
\text { menentukan tanaman } \\
\text { yang bisa ditanam } \\
\text { pada lahan dengan } \\
\text { kemiringan } 40^{\circ} \text { dan } \\
\text { yang masih memiliki } \\
\text { nilai ekonomis tinggi } \\
\text { bagi petani. } \\
\text { 2. Kegiatan penanaman } \\
\text { pohon di lahan sekitar } \\
\text { sumber air }\end{array}$ & $\begin{array}{l}\text { 1. Petani mengikuti } \\
\text { diskusi dan } \\
\text { pendampingan } \\
\text { penanaman pohon. } \\
\text { 2. Petani } \\
\text { memberikan lahan } \\
\text { yang seharusnya } \\
\text { ditanami pohon } \\
\text { dengan perakaran } \\
\text { kuat }\end{array}$ \\
\hline
\end{tabular}




\section{HASIL DAN PEMBAHASAN}

Hasil dari kegiatan penghijauan sebagai beikut.

1. Pemberdayaan masyarakat untuk meningkatan tingkat kesadaran lingkungan petani di sekitar sumber air Banyuning melalui kegiatan penghijauan.

2. Konservasi sumber daya air melalui penghijauan kembali lahan sekitar sumber air Banyuning dengan melakukan tanam pohon jeruk.

Sumber air Banyuning merupakan salah satu sumber air yang ada di hulu Sungai Brantas. Sumber air ini dimanfaatkan masyarakat Desa Punten untuk kebutuhan hidup seharihari dan juga sebagai sumber irigasi pada lahan pertanian. Selain Desa Punten, desa-desa lain di Kecamaan Bumiaji juga mengambil air dari sumber Banyuning untuk kebutuhan seharihari dan dimanfaatkan juga sebagai sumber irigasi.

Sumber air Banyuning dapat dijangkau dengan sepeda motor dan kondisi jalan sudah berpaving. Namun, permasalahan yang muncul yaitu kondisi lereng di samping jalan mengalami longsor. Berikut ini kondisi jalan menuju sumber air Banyuning.
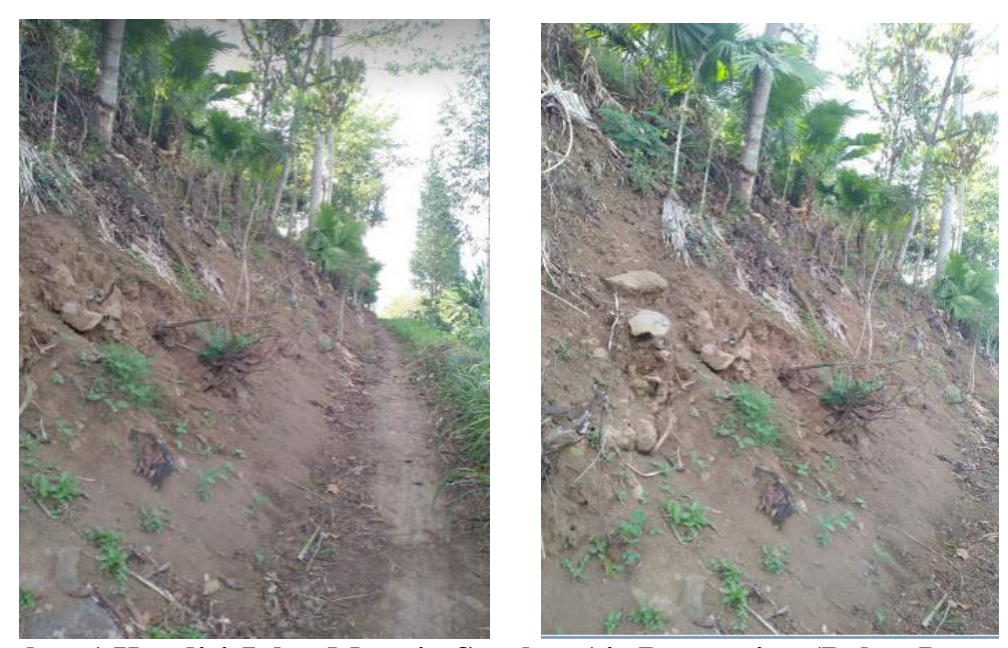

Gambar 1 Kondisi Jalan Menuju Sumber Air Banyuning (Bekas Longsoran)

Berdasarkan gambar 5.1 di atas diketahui bahwa masih ada beberapa lokasi sekitar sumber air yang tidak ada tanamannya. Kondisi lahan yang seperti ini mengancam keberadaan debit pada sumber air akan berkurang karena jumlah pohon yang menjadi media resapan air hujan ke dalam tanah berkurang.

Kondisi lahan lain yaitu lahan pertanian yang tepat berada di samping sumber air tidak ada tanaman pohon dengan perakaran kuat. Lahan pertanian hanya ditumbuhi rumput 
dan pohon pisang. Lahan pertanian ini berada pada kemiringan lereng lebih dari $40^{\circ}$. Seharusnya lahan ini ditumbuhi pohon dengan perakaran yang kuat, sehingga pada saat musim hujan tanah tidak longsor dan bisa menjadi media resapan air ke dalam tanah.
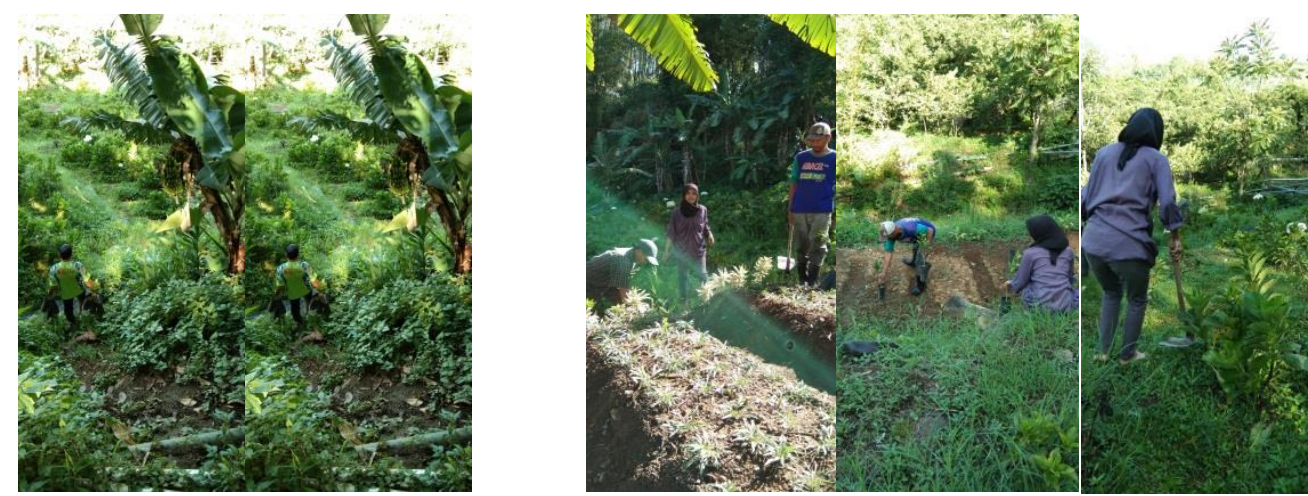

Gambar 2 Vegetasi Penutup Lahan di Samping Sumber Air Banyuning (Rumput (kiri), Pohon Pisang (kiri), Bunga Rotensia (kanan))

Sumber air Banyuning dimanfaatkan masyarakat sekitar dengan ditandon dan dialirkan melalui pipa-pipa yang tersambung ke rumah-rumah. Air sumber yang tidak ditandon akan mengalir melalui Sungai Brantas yang ada di bawah sumber air. Selanjutnya air sungai inilah yang dimanfaatkan untuk irigasi lahan pertanian.
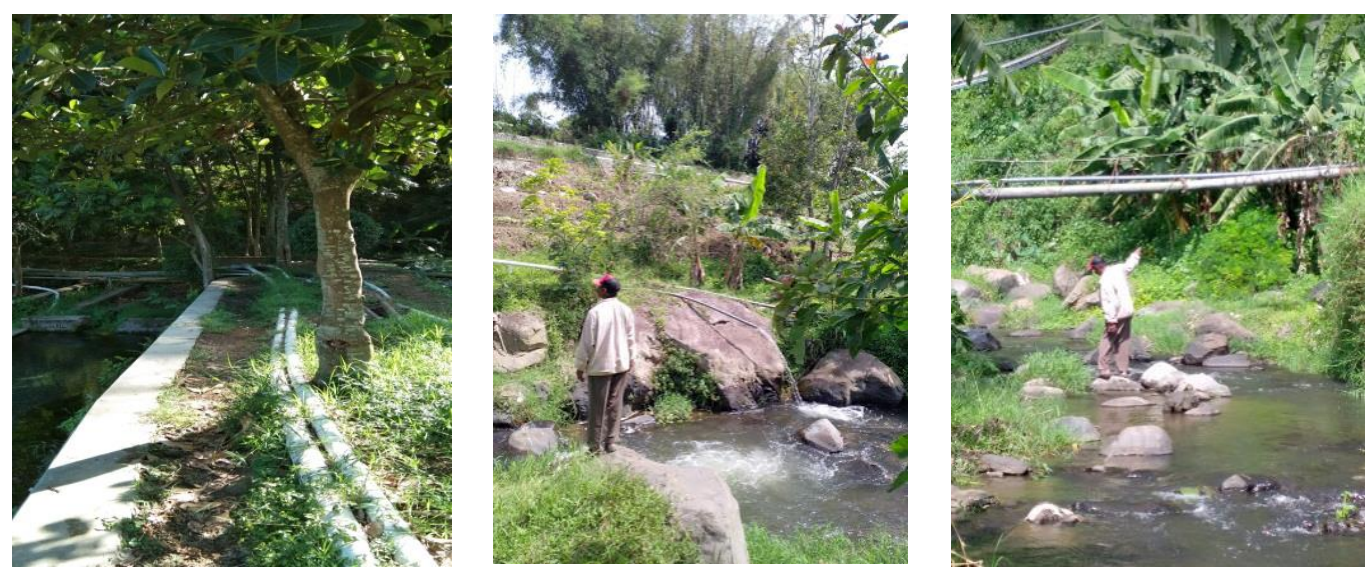

Gambar 3 Tandon Air dan Saluran Pipa (kiri), serta Sungai Brantas (kanan)

Berdasarkan kondisi sumber air Banyuning dilakukan pemberdayaan masyarakat petani di sekitar sumber untuk berpartisipasi dalam upaya konservasi sumber daya air. Petani yang memiliki lahan tepat di samping sumber harus menanami lahan dengan tanaman yang perakarannya kuat. Penentuan bibit pohon yang akan ditanam tidak serta merta ditentukan oleh pengabdi, tetapi melalui diskusi dengan petani. Hasil diskusi yaitu penanaman bibit 
dengan perakaran kuat dan masih memberikan nilai ekonomis bagi petani. Bibit yang ditentukan yaitu jeruk keprok punten.
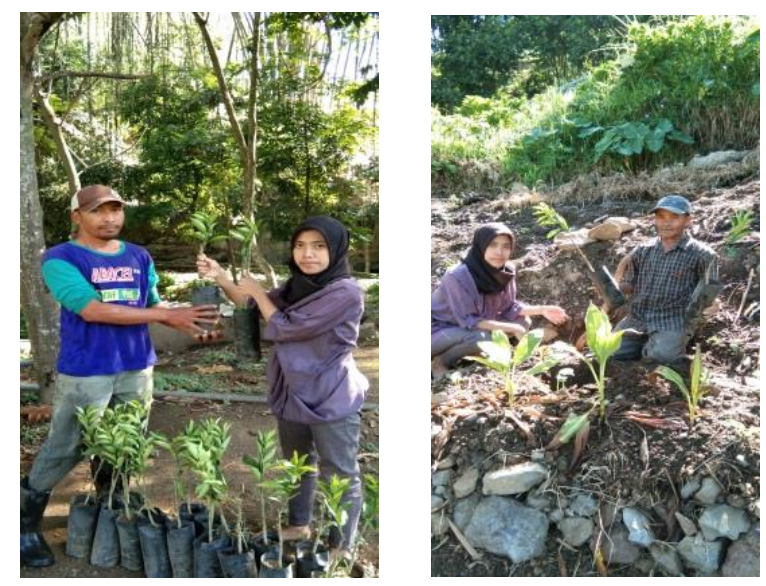

Gambar 4. Penyerahan Bibit Jeruk Keprok Punten

Petani bersedia lahan pertanian dengan kemiringan lereng lebih dari $40^{\circ}$ dibuat terasiring dan ditanami bibit jeruk dengan jarak $3 \mathrm{~m}$ antar tanaman. Penanaman dilakukan tepat di musim penghujan, sehingga bibit jeruk lebih mudah tumbuh. Diperkirakan bibit jeruk akan tumbuh menjadi besar dan menghasilkan buah yang bisa dijual yaitu sekitar 1,5 tahun.
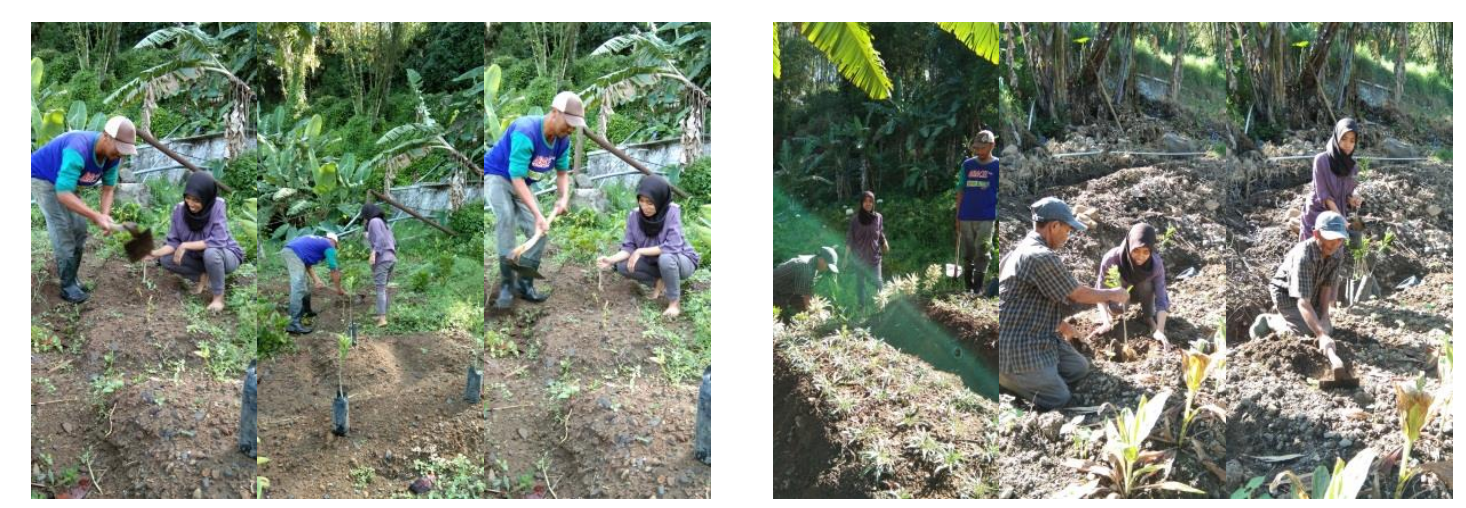

Gambar 5 Penanaman Bibit Jeruk Keprok Punten pada Lahan yang Sudah Dibuatkan Terasiring

Akar pohon jeruk yang sudah tumbuh besar bisa mencapai kedalaman $4 \mathrm{~m}$ dan akan menjadi perakaran yang kuat. Akar pohon jeruk yang sudah besar mampu menahan tanah dari erosi saat terjadi hujan. Akar pohon ini juga mampu meresapkan air hujan ke dalam tanah, sehingga air hujan tidak langsung lolos ke Sungai Brantas. Air hujan yang terinfiltrasi ke dalam tanah akan menjaga stabilitas debit air dalam tanah, khususnya sumber air Banyuning.

Kesediaan petani agar lahannya bisa ditanami pohon untuk mencegah longsor dan sebagai resapan air hujan merupakan wujud peningkatan kesadaran masyarakat terhadap 
kondisi alam. Petani menyadari bahwa lahan pertanian yang mereka miliki berada di sekitar sumber air, sehingga petani juga harus ikut berpartisipasi menjaga kelestarian sumber daya air.

Kegiatan tanam pohon selain sebagai wujud penghijaunan di sekitar sumber air Banyuning, juga bertujuan untuk meningkatkan kesadaran masyarakat akan pentingnya upaya mengelola sumber daya air yang dilakukan secara bijak dengan memperhatikan manfaat yang didapat serta mempertahankan komponen penyusunnya agar dapat dinikmati di masa mendatang. Tujuan ini sesuai dengan pengelolaan sumber daya air berkelanjutan.

Pengelolaan sumber daya air berkelanjutan mengacu pada tiga dimensi yaitu keberlanjutan pada dimensi ekonomi, sosial, dan lingkungan. Berikut ini manfaat keberlanjutan dari kegiatan penghijauan di sumber air Banyuning.

\section{Manfaat dalam Dimensi Ekonomi}

Bibit yang ditanam adalah bibit jeruk. Bibit ini akan tumbuh dan bisa menghasilkan buah pada umur 1,5 tahun. Buah jeruk bisa dijual petani dengan harga Rp 8.000,-/kg. Jika yang ditanam 20 bibit dengan perkiraan 1 pohon jeruk akan menghasilkan $20 \mathrm{~kg}$, maka akan panen buah jeruk bisa mencapai $400 \mathrm{~kg}$ dan petani bisa mendapatan $\mathrm{Rp}$ 3.200.000,- setiap kali panen. Petani bisa panen 2 kali dalam satu tahun karena dekat dengan sumber air dan mudah untuk irigasi.

\section{Manfaat dalam Dimensi Sosial}

Kegiatan penghijauan ini menghasilkan benefit berupa peningkatan kesadaran lingkungan masyarakat petani yang berada di sekitar sumber air dan bersedia lahan yang memiliki kemiringan lereng lebih dari $40^{\circ}$ untuk ditanami pohon dengan perakaran yang kuat. Jadi, pertanian yang dilakukan dengan sistem tumpang sari. Tanaman yang ditanam tidak hanya bunga Rotensia, tetapi ada tambahan pohon jeruk.

\section{Manfaat dalam Dimensi Lingkungan}

Lahan pertanian bunga Rotensia milik petani menjadikan nilaiguna lahan meningkat. Selain bisa menjadi sumber mata pencaharian petani, juga bisa menjaga lahan agar tidak mudah longsor dan menjadi resapan air hujan. Kegiatan penghijaun ini sebagai salah satu upaya konservasi sumber daya air agar bisa tetap terjaga kelestariannya dan bisa dimanfaatkan sampai generasi penerus. 


\section{SIMPULAN}

Kesimpulan dari kegiatan penghijauan di sekitar sumber air Banyuning ini sebagai berikut.

1. Meningkatkan partisipasi masyarakat dalam konservasi sumber daya air.

2. Meningkatkan kesadaran lingkungan masyarakat untuk menjaga kelestarian sumber daya air.

3. Menambah jumlah pohon tegakan dengan perakaran kuat di lahan sekitar sumber air yang memiliki kemiringan lereng lebih dari $40^{\circ}$.

Saran dalam kegiatan penghijauan di sekitar sumber air Banyuning ini sebagai berikut.

1. Penghijauan tidak hanya dilakukan oleh masyarakat petani yang memiliki lahan di sekitar sumber air. Tetapi juga diikuti dan dilakukan oleh masyarakat sekitar yang juga memanfaatkan sumber air Banyuning untuk kebutuhan sehari-hari, khususnya masayarakat yang tergabung dalam HIPPAM (Himpunan Penduduk Pengguna Air Minum) dan HIPPA (Himpunan Penduduk Pengguna Air, biasanya untuk irigasi lahan pertanian).

2. Kegiatan penghijauan setelah di lahan petani sekitar sumber, selanjutnya bisa dilakukan di lereng-lereng sekitar sumber air yang tidak ada tanamannya.

\section{DAFTAR PUSTAKA}

Damanhuri. 2004. Peningkatan Produksi Jeruk Melalui Pangkasan dan Pemupukan Berimbang. Makalah pada Pelatihan Penyuluh Agribisnis Jeruk Kabupaten Jember, Dinas Tanaman Pangan Kabupaten Jember 8 Agustus 2004

Poerwanto, R.2004. Program Pengembangan Jeruk Siem Di Indonesia. Prosiding Seminr Jeruk Siem Nasional. Pusat Penelitian dan Pengembangan Hortikultura Badan Penelitian danPengembangan Pertanian, (Jurnal: Surabaya 15-16 Juni).

Sallata, M. Kudeng. Konservasi Dan Pengelolaan Sumber Daya Air Berdasarkan Keberadaannya Sebagai Sumber Daya Alam. Balai Penelitian Kehutanan Makasar, (Jurnal: Info Teknis EBONI Vol. 12 No.1, Juli 2015: 75 - 86).

Subagyono. 2007. Konservasi Air Untuk Adaptasi Pertanian Terhadap Perubahan Iklim Bunga Rampai Konservasi Tanah dan Air. Pengurus Pusat MKTI Jakarta. 